\title{
PREPARATION AND CHARACTERIZATION OF GRAPEFRUIT OIL BASE MICROEMULSIONS OF CAFFEINE
}

\author{
EKAPOL LIMPONGSA, ${ }^{a, b}$, PATHOMTHAT SRISUKa, NAPAPHAK JAIPAKDEE ${ }^{a, b *}$
}

aDivision of Pharmaceutical Technology, Faculty of Pharmaceutical Sciences, Khon Kaen University, Khon Kaen, 40002, Thailand, bCenter for Research and Development of Herbal Health Products, Khon Kaen University, Khon Kaen, 40002, Thailand

Email: nj.jaipakdee@gmail.com

Received: 23 Nov 2018, Revised and Accepted: 12 Feb 2019

\section{ABSTRACT}

Objective: The objective of the present work was to prepare and characterize grapefruit oil base microemulsions loaded with caffeine as a model hydrophilic compound.

Methods: The formulation ingredients were selected based on surfactant efficiency and solubility studies. Ternary phase diagrams of grapefruit oil were constructed using the water titration method. Nine $\mathrm{O} / \mathrm{W}$ microemulsions were constructed and prepared by mixing surfactant system, grapefruit oil, water and caffeine together. The resulting microemulsions were investigated for viscosity using Brookfield viscometer, for $\mathrm{pH}$ value using a digital pH meter, and for average particle size and polydispersity index (PDI) using a Zetasizer Nano. Ex vivo skin permeation through porcine ear skin was conducted using a side-by-side diffusion cell. The amount of caffeine was analyzed using HPLC-UV method.

Results: Tween 20 yielded the highest emulsification ability for grapefruit oil and the highest caffeine solubility. It was selected as a major surfactant. Caffeine was slightly soluble in ethanol and isopropyl alcohol, but sparingly soluble in propylene glycol (PG). These ingredients were used as the cosurfactants. Nine grapefruit oil base microemulsions were prepared and characterized. The $\mathrm{pH}$ of microemulsions was within the range of 4.48-5.96. Particle size was in the range of $10.81 \pm 0.03$ to $62.18 \pm 21.04 \mu \mathrm{m}$ with the PDI of $0.13 \pm 0.02$ to $0.64 \pm 0.11$. Viscosity and particle size of microemulsions increased significantly with increasing grapefruit oil or tween 20 content. Addition of PG as cosurfactant resulted in the increases of viscosity, particle size and PDI. Depending on the formulation parameters, the permeation fluxes of caffeine from grapefruit oil base microemulsions were in the range of $28.4 \pm 3.4-361.4 \pm 15.2 \mu \mathrm{g} / \mathrm{cm} 2 / \mathrm{h}$

Conclusion: The grapefruit oil base microemulsions were successfully formulated. The physical properties and caffeine permeation of these microemulsions were found to be dependent on the grapefruit oil content, tween 20 content, cosurfactant type and content, as well as caffeine loading. The optimal formulation of grapefruit oil base microemulsion suggested composition of $5 \%$ grapefruit oil, $50 \%$ surfactant system (tween 20 and ethanol at the ratio of 9:1), and water.

Keywords: Grapefruit oil, Microemulsions, Caffeine

(C) 2019 The Authors. Published by Innovare Academic Sciences Pvt Ltd. This is an open access article under the CC BY license (http://creativecommons.org/licenses/by/4.0/] DOI: http://dx.doi.org/10.22159/ijap.2019v11i2.30958

\section{INTRODUCTION}

Microemulsion is a single, optically isotropic solution of water and oil stabilized by an interfacial film consisting of a surfactant, frequently in combination with cosurfactant. Over the past two decades, microemulsions have attracted considerable attention as a drug delivery vehicle for dermal application due to their ability to efficiently maximize the permeation flux into the skin. Microemulsions provide several advantages including thermodynamic stability, high solubilization capacity for hydrophilic and hydrophobic compounds, easy formation, low viscosity with Newtonian behavior, and small droplet size $(<150 \mathrm{~nm})[1-6]$.

Different oils have been used for the formulation of topical microemulsions. The oil selection was commonly based on its ability to solubilize a loading compound and/or ability to enhance skin permeation. Recently, few essential oils have been used as an oil phase in the formulation of topical microemulsions [7-9].

Grapefruit oil, an essential oil extracted from the peel of Citrus paradisi. L, is a mixture of volatile compounds with pleasant refreshing effect, and commonly used as a flavouring agent [10-13]. Grapefruit oil consists mainly of monoterpene hydrocarbons, and up to $90 \%$ of which is limonene [14]. As for the other terpenes, limonene is one of the effective permeation enhancers generally regarded as safe [15]. It has been reported that the addition of limonene into the oil phase of microemulsions further increased the skin permeation rate [16-18].

Caffeine, a naturally occurring purine-based alkaloid, is a popular psychotropic compound. It is clinically used as a central nervous system stimulant, and a treatment for apnea in premature neonates
[19-21]. Caffeine is also applied in cosmetic formulations mainly due to its antioxidant properties, as well as activities on fatty, connective tissues and microcirculation, which could help to improve gynoid lipodystrophy [22]. Caffeine is a hydrophilic substance (MW 194.19; $\mathrm{pK}_{\mathrm{a}}$ 10.4; $\left.\log \mathrm{P}-0.07\right)$ [23]. It is known that permeation of caffeine through the skin is compromised by its hydrophilicity, and a suitable delivery system could further increase the permeation flux [24, 25].

The objective of the present work was to prepare and characterize grapefruit oil base microemulsion formulations. Caffeine was used as a hydrophilic model compound. Oil-in-water (O/W) type microemulsion was selected based on the ability to enhance skin permeation [26], in addition to its greaseless and non-tackiness characteristics compared to the water-in-oil microemulsion. To identify a suitable microemulsion system for topical applications, the effect of concentrations of grapefruit oil (an oil phase), surfactant and cosurfactants on the characteristics and ex vivo permeation were studied.

\section{MATERIALS AND METHODS}

\section{Materials}

Caffeine (Reagentplus) was obtained from Sigma-aldrich (USA). Grapefruit oil was received from Thai-China Flavours and Fragrances Industry Co., Ltd. (Thailand). Tween 20 (ECOTERIC 20) and tween 80 (ECOTERIC 80) were purchased from Ajax Finechem Pty Ltd (Seven Hills, Australia). PEG-40 hydrogenated castor oil (Nikkol HCO-40, HCO40) was provided by Nikko Chemicals Co., Ltd. (Japan). Tween 60 was obtained from NamSiang Co., Ltd. (Thailand). Ethanol was purchased from Merck (Germany). Isopropyl alcohol (IPA) and glacial acetic acid were obtained from QRëC (New 
Zealand). Propylene glycol (PG) and methanol were purchased from RCI Labscan Ltd (Thailand). Deionized water was used throughout the study. All chemicals were used as received.

\section{Screening of formulation ingredients}

\section{Surfactant efficiency study}

The surfactant efficiency- $\mathrm{S}_{\min }$-defined as the minimum amount of surfactant required for completely homogenizing grapefruit oil and water to form a clear, isotropic, single phase microemulsion was determined [27]. The test surfactant was added drop by drop to the 1:1 weight ratio of grapefruit oil to water mixtures. The amount of surfactant required to change the grapefruit oil-water mixture appearance from turbid to transparent corresponded to the $S_{\min }$.

\section{Solubility study}

The solubility of caffeine in various surfactants and solvents was measured. Excess amount of caffeine was added to known weight of each surfactant or solvent, vortexed for 2 min followed by sonication (Elma Transsonic 700/H, Elma-Hans Schmidbauer, Germany) for 30 min in order to facilitate the saturation condition, and then equilibrated at $32 \pm 0.5{ }^{\circ} \mathrm{C}$ in a shaking water bath (Digital Temperature Controller, Polyscience, Germany) for $24 \mathrm{~h}$. Mixtures were filtrated through a membrane filter $(0.45 \mu \mathrm{m}, 13 \mathrm{~mm}$, Millipore filter, Millipore, Bedford, MA). The filtrated solution was then diluted and assayed by HPLC as described later.

\section{Construction of phase diagrams}

In order to determine the concentration range of components for the existing range of microemulsions, phase diagrams were constructed using the water titration method at ambient condition [1]. Briefly, mixtures of grapefruit oil with surfactant were prepared at weight ratios of 9:1, 8:2, 7:3, 6:4, 5:5, 4:6, 3:7, 2:8, 1:9 into different vials. These mixtures were titrated drop-wise with water. Following each addition, the mixtures were vortexed for 2-3 min and were allowed to equilibrate. After equilibration, the mixtures were examined visually for phase separation, transparency and flow properties. The point at which the mixture became turbid or showed signs of phase separation was considered the end point of the titration. The phase diagrams were drawn. The area of microemulsion existence was determined and denoted as ME.

The effects of cosurfactants, namely ethanol, IPA and PG on the microemulsion formation of tween 20-grapefruit oil-water, were also investigated. The selected surfactant (tween 20) was mixed with cosurfactant at weight ratios of $9 / 1,5 / 1$ and $1 / 1$ surfactant/cosurfactant ratio to obtain the surfactant systems. The pseudo-ternary phase diagrams were then constructed using the water titration method as previously described.

\section{Preparation of caffeine-loaded microemulsions}

The microemulsion formulations were prepared by mixing surfactant system (tween 20 or mixture of tween 20 with cosurfactant) and grapefruit oil together. The precise weight of caffeine was firstly dissolved in water and then added to the mixture of surfactant-grapefruit oil under moderate magnetic stirring for 30 min (at ambient temperature). The resulting microemulsions were tightly sealed and allowed to equilibrate at ambient temperature $\left(25-30{ }^{\circ} \mathrm{C}\right)$ for at least $12 \mathrm{~h}$ before further investigations.

\section{Characterization of caffeine-loaded microemulsions}

The physical form and appearance of the tested formulations were investigated visually. Only clear, isotropic one phase systems were considered microemulsions and further characterized. The $\mathrm{pH}$ values of microemulsions were determined at room temperature using a digital pH meter (Corning M250, Ciba Corning Ltd., UK). The viscosity of various microemulsions was measured at $32{ }^{\circ} \mathrm{C}$ employing a rotating Brookfield viscometer (Model DV-III; Brookfield Engineering Laboratories, Inc., MA, USA) equipped with small sample adapter (cylindrical sample chamber and spindle number 18).

The microemulsions were characterized for average particle size and polydispersity index (PDI) using a Zetasizer Nano (Malvern
Instruments, Malvern, Worcestershire, UK) at a temperature of $25 \pm 2$ ${ }^{\circ} \mathrm{C}$ and at $90^{\circ}$ to the incident beam applying the principle of photon correlation spectroscopy. Dispersions were 10-times diluted with prefiltered $(0.45 \mu \mathrm{m})$ ultrapure water to ensure that the light scattering intensity was within the instrument's sensitivity range.

\section{Ex vivo skin permeation study}

Porcine ears were obtained from a local slaughterhouse and cleaned with water. After soaking the ears in water at $60^{\circ} \mathrm{C}$ for $45 \mathrm{~s}$, the intact epidermis was peeled off with forceps, washed with water and kept at $-20^{\circ} \mathrm{C}$ until use (within $7 \mathrm{~d}$ ) [28]. The frozen skin of fullthickness was thawed at ambient temperature before use.

The ex vivo permeation of caffeine from the microemulsion through the pig ear skin was conducted using a side-by-side diffusion cell with a diffusion area of $0.694 \mathrm{~cm} 2$ (Crown Glass Company, USA). The system was connected to a water bath maintained at a temperature of $32 \pm 0.5^{\circ} \mathrm{C}$. A thawed skin was mounted between the donor and receptor compartments with a clamp and was hydrated with $\mathrm{pH} 7.4$ phosphate buffered saline (PBS) for $1 \mathrm{~h}$. The caffeine microemulsion ( $3 \mathrm{ml}$ ) was added to the donor compartment, which was in contact with the stratum corneum side of the skin. The receptor compartment was filled with $3 \mathrm{ml}$ of PBS solution. At predetermined times, $2.0-\mathrm{ml}$ samples were taken from the receptor compartment and equal volumes of PBS solution were immediately added after each sampling. The concentration of caffeine was analyzed by HPLC. The cumulative amount of caffeine that permeated the skin was plotted against time.

\section{Data analysis}

The steady state flux $\left(U_{s s}\right)$, the permeability coefficient $\left(k_{p}\right)$, the concentration gradient $(\Delta C)$, and the drug concentration in the vehicle $\left(C_{v}\right)$ are defined by equation 1 [29].

$$
J_{s s}=k_{p} \cdot \Delta C=k_{p} \cdot C_{v}
$$

The permeability coefficient from permeation through pig ear skin and the lag time $\left(T_{\text {lag }}\right)$ are defined by equations 2 and 3 .

$$
\begin{aligned}
& k_{p}=\frac{K \cdot D}{h} \\
& T_{\text {lag }}=\frac{h^{2}}{6 D}
\end{aligned}
$$

Where $K$ is the partition coefficient of the drug in the skin and in the vehicle; $D$ is the diffusion coefficient of the drug in the skin; $h$ is the thickness of the skin.

\section{HPLC analysis}

Caffeine content was determined using an HPLC system (PerkinElmer, MA) consisting of a UV/VIS detector (model 785A) and a pump (series 200 LC). The chromatographic separation was achieved on a Hypersil Gold C-18 column $(250 \mathrm{~mm} \times 4.6 \mathrm{~mm}, 5 \mu \mathrm{m}$; Thermo Electron Corporation, USA) with a flow rate of $1 \mathrm{ml} / \mathrm{min}$ with UV detection at $274 \mathrm{~nm}$. The mobile phase consisted of methanol, water, and glacial acetic acid at a volume ratio of 45.0: 53.5: 1.5. The retention time of caffeine was approximately $5.2 \mathrm{~min}$. The standard curve was linear over a concentration range of 5 to 66 $\mu \mathrm{g} / \mathrm{ml}$ with $R 2$ value $>0.99$. The day-to-day relative standard deviations (RSD) for this assay were less than $2 \%$.

\section{Statistical analysis}

Each experiment was repeated at least three times. The results are expressed as mean \pm SD. One-way analysis of variance was used to test the statistical significance of differences among groups. Statistical significance of the differences of the means was determined using Student's $t$-test. All statistical tests were run using the SPSS program for MS Windows, release 19 (SPSS (Thailand) Co. Ltd., Bangkok, Thailand). The significance was determined with $95 \%$ confidence limits $(\alpha=0.5)$ and was considered significant at a level of $\mathrm{P}$ less than 0.05 . 
Table 1: Surfactant efficiency ( $S_{\min }$ ) of the investigated surfactants for grapefruit oil

\begin{tabular}{ll}
\hline Surfactants & $\mathbf{S}_{\min }(\mathbf{\%} / \mathbf{w})^{*}$ \\
\hline Tween 20 & $52.88 \pm 0.16$ \\
Tween 60 & $65.75 \pm 0.77$ \\
Tween 80 & $73.69 \pm 1.14$ \\
HC040 & $61.27 \pm 1.46$ \\
\hline
\end{tabular}

${ }^{*}$ mean \pm SD, $n=3$.

\section{RESULTS AND DISCUSSION}

\section{Screening of components for microemulsions}

In the formulation of microemulsions, it is important to determine which surfactants have good affinity with the given oil. In this study, four nonionic surfactants (tween 20, tween 60, tween 80 and HCO40) were investigated due to their low skin irritation and lower tendency to cause allergic reactions, commercial availability and inexpensiveness [3]. The emulsification ability of the investigated surfactants in terms of $S_{\min }$ or the determined amount of surfactant required to completely solubilize equal masses of grapefruit oil and water was determined. As shown in table 1 , the lowest $\mathrm{S}_{\min }(52.88 \pm 0.16 \% \mathrm{w} / \mathrm{w})$ were observed with tween 20 , which has the shortest chain length (C-12) with the highest hydrophilicity (HLB 16.7) [30].

It is known that drug loading is one of the major parameters for formulation designation. Because the solubility of caffeine in grapefruit oil was found to be relatively low (less than $1 \mathrm{mg} / \mathrm{g}$ ), the surfactant system with good solubilization capacities for caffeine was therefore needed. The solubility of caffeine in the investigated surfactants, as well as cosurfactants, was determined and the results are shown in table 2. Caffeine is soluble in water, with solubility (at $32{ }^{\circ} \mathrm{C}$ ) of $30.68 \pm 0.92 \mathrm{mg} / \mathrm{g}$. Amongst the investigated surfactants, the solubility of caffeine was the highest in tween 20 , followed by tween 80, HCO40 and tween 60 , respectively. Given its relatively high solubility, coupled with high emulsification ability for grapefruit oil, tween 20 was therefore selected as a surfactant for preparation of the grapefruit oil microemulsions. Tween 20 is a widely accepted nonionic surfactant and used in various pharmaceutical formulations [31].

Caffeine was slightly soluble in ethanol and IPA, but sparingly soluble in PG. Due to their ability to act as a permeation enhancer and relatively high skin tolerance [32], these ingredients were therefore used as the cosurfactants. It is known that the presence of cosurfactant might overcome the need for any additional input of energy. These properties make the components useful as vehicles for drug delivery.

Table 2: Solubility of caffeine in various surfactants and cosurfactants at $32{ }^{\circ} \mathrm{C}$

\begin{tabular}{ll}
\hline Surfactants/Cosurfactants & ${\text { Solubility } \mathbf{~ ( m g / g ) ~}^{*}}^{\text {Tween } 20}$ \\
Tween 60 & $10.12 \pm 1.50$ \\
Tween 80 & $5.87 \pm 1.22$ \\
HCO40 & $9.23 \pm 1.44$ \\
Ethanol & $7.06 \pm 0.51$ \\
IPA & $9.39 \pm 0.19$ \\
PG & $7.38 \pm 0.45$ \\
Deionized water & $16.40 \pm 1.88$ \\
PBS pH 7.4 & $30.68 \pm 0.92$ \\
\hline
\end{tabular}

${ }^{*}$ mean \pm SD, $\mathrm{n}=3$.

\section{Ternary and pseudoternary phase diagrams of grapefruit oil}

The construction of ternary phase diagrams is used to determine the concentration range of constituents in the existing range of microemulsion. Ternary phase diagram of tween 20, grapefruit oil and water system is shown in fig. 1. The isotropic region with low viscosity is presented in the phase diagram as the one-phase microemulsion region. The rest of the phase diagram represents the turbid and conventional emulsions based on visual observation. Tween 20 alone could yield a considerable microemulsion region (33.4\%). It can be seen that grapefruit oil base microemulsion in the present study formed spontaneously at ambient temperature when their components were brought in contact.

The use of tween 20 alone as a surfactant is likely to sufficiently reduce the interfacial tension between grapefruit oil and water to form stable microemulsion. However, alcoholic cosurfactants like ethanol, IPA and PG could further increase the mobility of hydrocarbon tail, decrease the interfacial tension, and thereby further improve the microemulsification performance.

The effect of the investigated cosurfactants on the isotropic region of grapefruit oil-tween 20 -water system is presented in fig. 2 . The mixing ratios of surfactant to cosurfactant $\left(\mathrm{K}_{\mathrm{m}}\right)$ considered were 9:1, 5:1 and 1:1, respectively. The obtained ME regions generally increased in line with additions of these cosurfactants, except for 1:1 tween 20: PG system. For ethanol and PG, the ME regions obtained from $K_{m}$ of 9:1 and 5:1 were comparable, and the ME regions for ethanol and PG were $45.3-45.7 \%$ and $42.5-43.9 \%$, respectively. Increase cosurfactant ratio $\left(K_{m}=1: 1\right)$ resulted in the decrease in $M E$ regions compared to the lower cosurfactant ratio. In the case of IPA, the ME regions were comparable (43.0-47.3\%), regardless of the $\mathrm{K}_{\mathrm{m}}$.

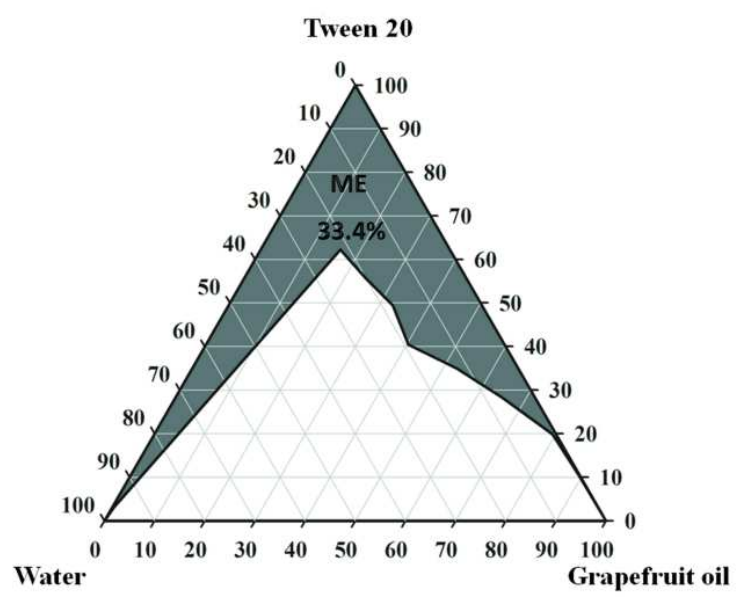

Fig. 1: Ternary phase diagram of grapefruit oil-water-tween 20 system. The gray area represents the region of microemulsion (ME) 
[A] Ethanol
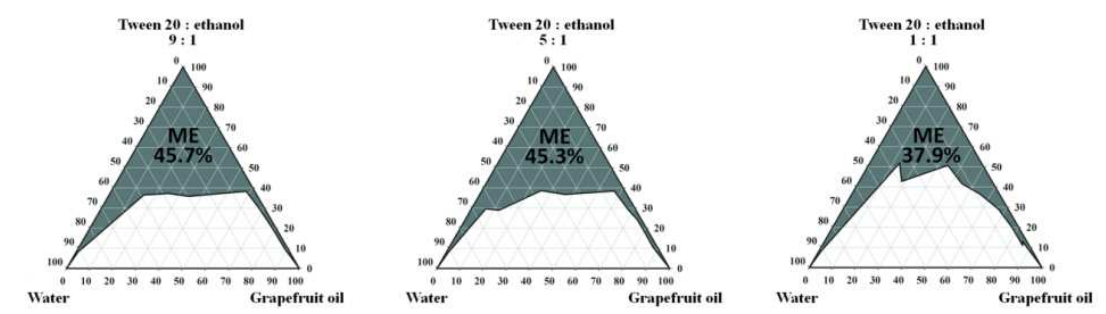

[B] IPA
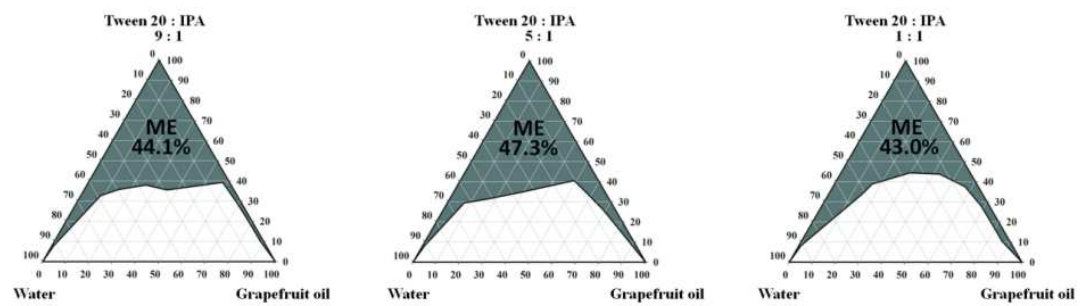

$[$ C] PG
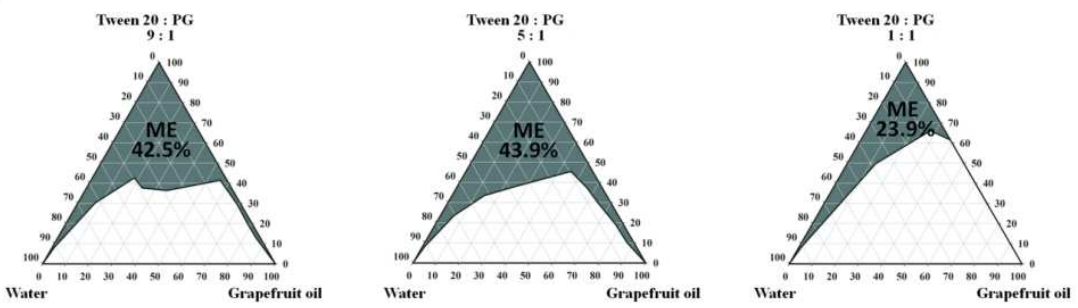

Fig. 2: Pseudoternary phase diagrams of grapefruit oil microemulsions formulated with surfactant mixtures containing tween 20 as surfactant (S) and [A] ethanol, [B] IPA and [C] PG as cosurfactant (CoS) with the weight ratios of S/CoS of 9/1, 5/1 and 1/1, respectively. The gray area represents the region of microemulsion (ME)

For the pseudoternary phase diagrams, the grapefruit oil microemulsion bases were designed. In our study, the 0/W microemulsion type with low oil content $(\leq 15 \% \mathrm{w})$ was considered. Furthermore, considering the problems associated with the use of a high amount of solvents as the cosurfactant, formulations with low cosurfactant or cosurfactant free microemulsion were attempted. Nine microemulsion bases were constructed and prepared (microemulsion bases for G1-G9). The preliminary results confirmed that these nine bases were $0 / W$ microemulsions. Therefore, these grapefruit oil microemulsions were further used for preparing caffeine loaded microemulsions.

Table 3: Composition of grapefruit oil microemulsions

\begin{tabular}{|c|c|c|c|c|c|c|c|}
\hline \multirow[t]{2}{*}{ Formulation } & \multirow[t]{2}{*}{ Tween 20} & \multicolumn{3}{|c|}{ Co-surfactants } & \multirow[t]{2}{*}{ Grapefruit oil } & \multirow[t]{2}{*}{ Water } & \multirow[t]{2}{*}{ Caffeine } \\
\hline & & Ethanol & IPA & PG & & & \\
\hline G1 & 50 & - & - & - & 5 & 44 & 1 \\
\hline G2 & 50 & - & - & - & 10 & 39 & 1 \\
\hline G3 & 50 & - & - & - & 15 & 34 & 1 \\
\hline G4 & 60 & - & - & - & 5 & 34 & 1 \\
\hline G5 & 70 & - & - & - & 5 & 24 & 1 \\
\hline G6 & 45 & 5 & - & - & 5 & 44 & 1 \\
\hline G7 & 45 & - & 5 & - & 5 & 44 & 1 \\
\hline G8 & 45 & - & - & 5 & 5 & 44 & 1 \\
\hline G9 & 35 & - & 15 & - & 5 & 44 & 1 \\
\hline G10 & 45 & 5 & - & - & 5 & 43 & 2 \\
\hline
\end{tabular}

Table 4: Viscosity, pH, particle size and PDI of the caffeine-loaded grapefruit oil microemulsions

\begin{tabular}{llll}
\hline Formulation & Viscosity (cP) & pH $^{*}$ & Particle size (nm) $^{*}$ \\
\hline G1 & $197.67 \pm 3.21$ & $4.48 \pm 0.03$ & $11.34 \pm 0.58$ \\
G2 & $301.50 \pm 6.66$ & $4.51 \pm 0.02$ & $13.13 \pm 0.77$ \\
G3 & $403.00 \pm 55.75$ & $4.54 \pm 0.01$ & $62.18 \pm 21.04$ \\
G4 & $328.70 \pm 3.29$ & $5.58 \pm 0.05$ & $30.81 \pm 10.25$ \\
G5 & $353.40 \pm 35.81$ & $5.96 \pm 0.06$ & $10.81 \pm 0.03$ \\
G6 & $194.33 \pm 4.51$ & $4.89 \pm 0.02$ & $17.46 \pm 8.33$ \\
G7 & $204.40 \pm 7.23$ & $5.12 \pm 0.02$ & $36.79 \pm 13.52$ \\
G8 & $227.33 \pm 6.51$ & $4.39 \pm 0.01$ & $16.12 \pm 1.00$ \\
G9 & $114.00 \pm 3.02$ & $4.96 \pm 0.02$ & $22.45 \pm 5.56$ \\
G10 & $192.00 \pm 2.65$ & $4.93 \pm 0.06$ & $0.03 \pm 0.14$ \\
\hline
\end{tabular}

${ }^{*}$ mean $\pm \mathrm{SD}, \mathrm{n}=3$. 


\section{Caffeine-loaded microemulsions}

\section{Effects of composition on the properties of caffeine-loaded} microemulsions

The composition of caffeine-loaded grapefruit oil microemulsion formulations are shown in table 3. These microemulsions were further analyzed for viscosity, $\mathrm{pH}$, particle size and PDI. The effects of composition on the microemulsion properties were shown in table 4 .

\section{Effects of grapefruit oil content}

The effects of grapefruit oil content on microemulsion properties were investigated in cosurfactant free formulations, G1-G3. As shown in table 4, the viscosity and particle size of the microemulsions increased significantly when grapefruit oil content increased from $5 \%$ to $10 \%$ and $15 \%$, respectively $(* \mathrm{P}<0.05)$. However, the PDI of microemulsions significantly increased only at $15 \%$ oil $(* \mathrm{P}<0.05)$. The average $\mathrm{pH}$ of microemulsions was comparable within the range of 4.48-4.54.

These results were in agreement with the previous study which reported the effects of limonene content on the viscosity of minoxidil microemulsions [33]. It is known that an increase of internal phase fraction in microemulsions results in increased viscosity of the system. Ma et al. [34] reported that increased oil content (Labrafil M 1944 CS) resulted in increases in particle size and PDI of caffeine microemulsions. The increased oil content also resulted in decreased water content. The viscosity of grapefruit oil $(1.07 \mathrm{cP})$ is higher than that of water $(0.89 \mathrm{cP})[31,35]$. The increased oil content might lead to higher viscosity which could impede the function of surfactant, resulting in increases in particle size and PDI of an emulsion. The lower oil phase content seems to be appropriate for preparation of microemulsion with smaller particle size.

\section{Effects of tween 20 content}

The effects of tween 20 content on microemulsion properties were investigated in formulations G1, G4, and G5 as shown in table 4. The average $\mathrm{pH}$ of these microemulsion formulations was in the range of 4.48-5.96. Increasing concentration of tween 20 from $50 \%$ to $60 \%$ resulted in significant increases in viscosity, particle size and PDI $\left({ }^{*} \mathrm{P}<0.05\right)$, whereas increasing concentration of tween 20 from $60 \%$ to $70 \%$ had no further effect on the viscosity and $\mathrm{pH}(\mathrm{P}>0.05)$, but resulted in significant decreases in the particle size and PDI $\left({ }^{*} \mathrm{P}<0.05\right)$.

These findings were in agreement with the previous study which reported the effects of tween 20 content on the viscosity of minoxidil microemulsions [33]. Patel et al. [36] reported that increasing surfactant system content resulted in increased particle size of fluconazole microemulsions. The reason behind these results may relate to the higher viscosity of tween $20(400 \mathrm{cP})$ compared to that of water [31]. The lower amount of surfactant system seems to be appropriate for preparation of microemulsions with smaller particle size.

Therefore, the contents of $5 \%$ grapefruit oil and 50\% surfactant system were used in further formulations because they showed the lowest viscosity and smallest particle size with low PDI.

\section{Effects of cosurfactant type and content}

The effects of the cosurfactant type were investigated in formulations G6-G8. As compared to the formulation without cosurfactant (G1), the addition of $5 \%$ ethanol had no effect on viscosity, particle size and PDI ( $P>0.05)$. The addition of IPA had no effect on viscosity $(P>0.05)$, but resulted in significant increases in particle size and PDI of microemulsion $\left({ }^{*} \mathrm{P}<0.05\right)$. The addition of $\mathrm{PG}$ resulted in significant increases in viscosity, particle size and PDI of microemulsion $(* \mathrm{P}<0.05)$. The formulation with all cosurfactants showed comparable particle size $(\mathrm{P}>0.05)$. The average $\mathrm{PDI}$ and $\mathrm{pH}$ of microemulsion with different cosurfactant were in the range of 0.32-0.64 and 4.39-5.12, respectively. Amongst these 3 formulations, microemulsion with PG (G8) as cosurfactants had significantly higher viscosity compared to those of ethanol and IPA (G6 and G7) $\left({ }^{*} \mathrm{P}<0.05\right)$.
The rank order of viscosity and molecular weight of the cosurfactant were $\mathrm{PG}>\mathrm{IPA}>$ ethanol $(58.1,2.43$ and $1.22 \mathrm{cP}$ for viscosity and 76.09, 60.1 and 46.07 for molecular weight, respectively) [31]. The greater viscosity and molecular weight of PG might cause a higher viscosity formulation as compared to other investigated cosurfactants.

The effects of cosurfactant content (IPA) were investigated in formulations G7 and G9. Increasing concentration of IPA from 5\% to $15 \%$ resulted in significantly lower viscosity $\left({ }^{*} \mathrm{P}<0.05\right)$. The particle size and PDI of microemulsion did not change $(P>0.05)$. The average $\mathrm{pH}$ of microemulsion was in the range of 4.96-5.12.

Increasing IPA content also resulted in decreased tween 20 content. It was reported that the viscosity of tween 20 was approximately $400 \mathrm{cP}$ [31] which was much higher than that of IPA. Lowering tween 20 content by $10 \%$ might be the reason for the lower viscosity. Additionally, the higher cosurfactant content may result in the higher number of cosurfactant molecules located at an oil-water interface of the microemulsion region, which would decrease the fluidity of the interfacial film, and therefore the apparent viscosity of the system.

\section{Effects of caffeine content}

The effects of caffeine content were also investigated. As shown in table 4 , increasing the concentration of caffeine from $1 \%$ (G6) to $2 \%$ (G10) had no effect on the physical characteristics of the resulting microemulsion.

\section{Effects of composition on the ex vivo permeation of caffeine- loaded microemulsions}

The transdermal/topical delivery is a complex phenomenon governing the release from the vehicle, the enhancement of vehicle potency and partitioning of drug into the skin. The release of drug from a vehicle into the skin and the diffusion across the skin are controlled by physicochemical factors sensitive to the molecular properties of the drug, the vehicle and the skin [37]. The delivery process can be affected by interactions that occur between the drug and skin, vehicle and skin, drug and vehicle, and drug, vehicle and skin. The permeation profiles and calculated parameters of caffeine from grapefruit oil microemulsions are shown in fig. 3 and table 5, respectively.

\section{Effects of grapefruit oil content}

The effects of grapefruit oil content (G1-G3) on permeation profiles, fluxes and parameters are shown in fig. $3 \mathrm{~A}$ and table 5 . As seen in fig. $3 \mathrm{~A}$, the caffeine microemulsions with $5 \%$ and $10 \%$ grapefruit oil showed comparable permeation profiles; however, the microemulsion with $15 \%$ grapefruit oil showed less permeability. It was noted from table 5 that increasing concentration of grapefruit oil from $5 \%$ to $10 \%$ had no effect on both permeation flux and the lag time $(P>0.05)$. Consequently, comparability in other permeation parameters was therefore observed. However, increasing oil concentration to $15 \%$ resulted in decreased flux, but at the same time, lag time increased significantly $\left({ }^{*} \mathrm{P}<0.05\right)$. As a result, the $k_{p}$ and $D$ decreased but the $K$ increased significantly $\left({ }^{*} \mathrm{P}<0.05\right)$.

Considering the permeation parameters in equation (1), since the caffeine concentration was fixed, the decrease in permeation flux $\left.U_{s s}\right)$ was the result of the decreased permeability coefficient $\left(k_{P}\right)$. Based on equation (2), the $k_{P}$ depends on the partition coefficient of drug between skin and formulation $(K)$ and diffusion coefficient of drug in skin $(D)$ [29]. Therefore, the lower $J_{s s}$ of caffeine from the microemulsions might be the effect of the decreased $K$ and/or $D$. According to equation (3), the lag time is a permeation parameter that mainly depends on the $D$ of the drug through the skin $[8,29]$. The increase in lag time of caffeine from the microemulsions was the effect of the decreased $D$. Caffeine, i.e., a small, hydrophilic molecular compound with low solubility in grapefruit oil and low $\log K_{\text {oct }}$ value [23]. Therefore, it is expected to diffuse easily in the $\mathrm{O} / \mathrm{W}$ microemulsion. Increasing viscosity of microemulsion with internal oil content may impede the drug diffusion in the formulation. Moreover, the lower affinity of drug to the grapefruit oil could be the reason for the increase in caffeine partition coefficient. The major component of grapefruit oil is limonene [14]. This finding is in agreement with the study on minoxidil microemulsion composed of limonene [33]. 

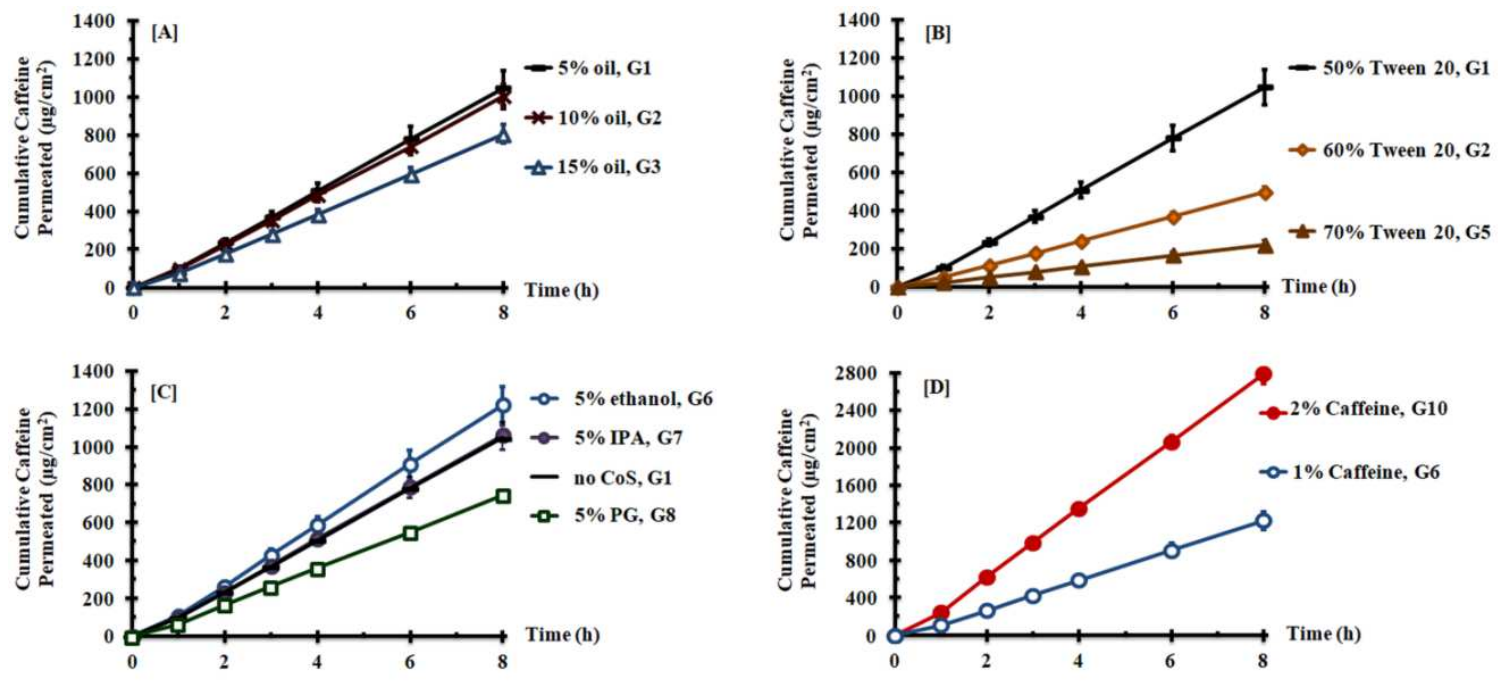

Fig. 3: Permeation profiles of caffeine through porcine ear skin from various grapefruit oil microemulsion formulations prepared with different oil phase content $[A]$, surfactant (tween 20) content [B], types of cosurfactants [C] and caffeine loading [D] (mean \pm SD, $n=5$ )

Table 5: Permeation fluxes and parameters of caffeine from grapefruit oil microemulsion

\begin{tabular}{llllll}
\hline Formulation & $\begin{array}{l}\text { Permeation flux } \\
(\boldsymbol{\mu g} / \mathbf{c m} \mathbf{2} / \mathbf{h})^{*}\end{array}$ & $\begin{array}{l}\text { Lag time } \\
(\mathbf{h})^{*}\end{array}$ & $\begin{array}{l}\text { Permeability coefficient }\left(\boldsymbol{k}_{\boldsymbol{p}}\right) \\
(\mathbf{c m} / \mathbf{h}) \times \mathbf{1 0}^{*} \mathbf{3}^{*}\end{array}$ & $\begin{array}{l}\text { Diffusion coefficient } \\
(\boldsymbol{D})(\mathbf{c m} \mathbf{2} / \mathbf{h}) \times \mathbf{1 0}-\mathbf{3}^{*}\end{array}$ & $\begin{array}{l}\text { Partition coefficient } \\
(\boldsymbol{K})^{*}\end{array}$ \\
\hline G1 & $135.61 \pm 11.88$ & $0.27 \pm 0.05$ & $13.55 \pm 1.19$ & $14.37 \pm 2.27$ & $145.02 \pm 29.34$ \\
G2 & $129.39 \pm 8.30$ & $0.26 \pm 0.07$ & $12.94 \pm 0.83$ & $15.26 \pm 3.99$ & $134.48 \pm 36.29$ \\
G3 & $104.51 \pm 5.90$ & $0.75 \pm 0.05$ & $10.46 \pm 0.59$ & $5.01 \pm 0.34$ & $313.97 \pm 23.04$ \\
G4 & $64.29 \pm 3.84$ & $0.08 \pm 0.02$ & $6.35 \pm 0.38$ & $50.98 \pm 18.18$ & $20.01 \pm 4.83$ \\
G5 & $28.41 \pm 3.40$ & $0.05 \pm 0.01$ & $2.82 \pm 0.34$ & $96.31 \pm 29.50$ & $5.04 \pm 1.64$ \\
G6 & $178.24 \pm 16.83$ & $0.55 \pm 0.15$ & $17.83 \pm 1.68$ & $6.73 \pm 1.48$ & $404.55 \pm 103.47$ \\
G7 & $137.49 \pm 11.15$ & $0.28 \pm 0.11$ & $13.75 \pm 1.11$ & $14.72 \pm 4.56$ & $155.89 \pm 72.81$ \\
G8 & $96.89 \pm 2.76$ & $0.30 \pm 0.08$ & $9.70 \pm 0.28$ & $12.89 \pm 2.00$ & $115.12 \pm 25.92$ \\
G9 & $127.39 \pm 10.71$ & $0.20 \pm 0.07$ & $12.42 \pm 1.04$ & $15.95 \pm 4.19$ & $110.72 \pm 32.80$ \\
G10 & $361.41 \pm 15.17$ & $0.27 \pm 0.07$ & $18.06 \pm 0.76$ & $11.43 \pm 1.52$ & $217.40 \pm 36.78$ \\
\hline
\end{tabular}

${ }^{*}$ mean \pm SD, $n=5$.

\section{Effects of surfactant content}

The effects of surfactant content (G1, G4, and G5) on permeation profiles, fluxes and parameters are shown in fig. 3B and table 5 . As seen in fig. 3B, the microemulsions with $50 \%$ tween 20 showed the highest permeation profile, followed by those with $60 \%$ and $70 \%$ tween 20, respectively. Increasing concentration of tween 20 from $50 \%$ to $60 \%$ and $70 \%$ resulted in significant decreases in flux and lag time $\left({ }^{*} \mathrm{P}<0.05\right)$. As a result, the $k_{p}$ and $K$ decreased but the $D$ increased significantly $\left({ }^{*} \mathrm{P}<0.05\right)$. Tween 20 is a non-ionic surfactant that can influence the skin barrier, and act as permeation enhancers [38]. However, increasing surfactant content resulted in decreased aqueous phase content, but increased viscosity. Water in aqueous phase could hydrate stratum corneum, leading to an increase in drug partition and permeation [36]. Less water content resulted in lower solubility, and in turn led to shorter lag time and higher $D$. Increasing viscosity of microemulsion with tween 20 content may impede the drug diffusion in the formulation. Moreover, less aqueous phase resulted in lower partition $(K)$ of caffeine into stratum corneum. Therefore, the permeation of caffeine decreased.

\section{Effects of cosurfactant type and content}

The permeation profiles of microemulsions with and without different cosurfactant were shown in fig. 3C. The microemulsion with ethanol showed the highest permeation profile followed by those with IPA and PG, respectively. The microemulsion without cosurfactant showed comparable permeation profile with the microemulsion with IPA. It could be seen in table 5 that the addition of ethanol resulted in the increases in flux and lag time when compared to those of formulations without cosurfactant. As a result, the $k_{p}$ and $K$ increased, while $D$ decreased. The addition of IPA had no effect on the flux, lag time and other parameters. However, the addition of PG resulted in the decrease in flux but had no effect on lag time. As a result, $k_{p}$ decreased, whereas $D$ and $K$ did not change.

This finding was in contrast to the previous study [39] which reported the higher permeation profile of caffeine from the vehicle containing 5\% PG compared to 5\% ethanol. The differences in caffeine concentration and dosage form used should be noted.

The viscosity of microemulsion containing PG was higher than that containing ethanol. It could impede the diffusion of caffeine in the formulation. Moreover, as reported in table 2, the solubility of caffeine in PG was higher than that in ethanol. The higher affinity of the drug to the vehicle could be the reason for the decrease in caffeine partition coefficient. As a result, the lower permeation of caffeine was shown.

The effects of IPA content on permeation of caffeine were also investigated in formulations G7 (5\%) and G9 (15\%). It was clearly found that there was no effect on the permeation of caffeine.

\section{Effects of caffeine content}

The effects of caffeine content were investigated in formulations G6 $(1 \%)$ and G10 (2\%). It was found that increasing caffeine content resulted in increased flux but decreased lag time $\left({ }^{*} \mathrm{P}<0.05\right)$. The $k_{p}$ did not change. The $D$ increased but the $K$ decreased.

Increasing caffeine content resulted in an increased concentration gradient. As seen in table 3, decrease in water leads to less polarity of the formulation. The lower affinity of the drug to formulation resulted in higher diffusivity of drug. 


\section{CONCLUSION}

The grapefruit oil base microemulsions were successfully formulated and prepared. The physical properties, as well as permeation of hydrophilic compound like caffeine, depended on the grapefruit oil content, tween 20 content, cosurfactant type and content, as well as caffeine loading. The $0 / \mathrm{W}$ microemulsions composed of $5 \%$ grapefruit oil, $50 \%$ surfactant system (tween 20 and ethanol at the ratio of 9:1), and water adjusted to $100 \%$ gave optimal microemulsion properties in respect of viscosity, $\mathrm{pH}$, particle size, PDI and ex vivo permeation. The physicochemical characteristics suggest that these grapefruit oil base microemulsions can potentially be vehicles for drug-carrier and cosmetic products. Further studies including in vivo study are to be performed.

\section{Acknowledgment}

The research was financially supported by the Center for Research and Development of Herbal Health Products, Khon Kaen University, Thailand. The authors are also grateful to the Faculty of Pharmaceutical Sciences, Khon Kaen University (Khon Kaen, Thailand) for its technical facilities.

\section{AUTHORS CONTRIBUTIONS}

All the authors have contributed equally

\section{CONFLICT OF INTERESTS}

The authors report no conflicts of interest

\section{REFERENCES}

1. Santos P, Watkinson AC, Hadgraft J, Lane ME. Application of microemulsions in dermal and transdermal drug delivery. Skin Pharmacol Physiol 2008;21:246-59.

2. Lawrence MJ, Rees GD. Microemulsion-based media as novel drug delivery systems. Adv Drug Delivery Rev 2012;64:175-93.

3. Kreilgaard M. Influence of microemulsions on cutaneous drug delivery. Adv Drug Delivery Rev 2002;54:S77-98.

4. Chaiyana W, Phongpradist R, Leelapornpisid P. Characterization of hydrodistillated pomelo peel oil and the enhancement of biological activities using microemulsion formulations. Int J Pharm Pharm Sci 2014;6:596-602.

5. Lavanya N, Aparna C, Umamahesh B. Formulation and evaluation of glipizide microemulsion. Int J Pharm Pharm Sci 2016;8:171-6.

6. Ebenazer A, Franklyne JS, Mukherjee A, Chandrasekaran N. Development of azithromycin loaded lemongrass oil based microemulsion and determination of antibacterial potential. Int J Appl Pharm 2018;10:72-81.

7. Biruss B, Kahlig H, Valenta C. Evaluation of a eucalyptus oil containing topical drug delivery system for selected steroid hormones. Int J Pharm 2007;328:142-51.

8. El Maghraby GM. Transdermal delivery of hydrocortisone from eucalyptus oil microemulsion: effects of cosurfactants. Int J Pharm 2008;355:285-92.

9. Chaiyana W, Saeio K, Hennink WE, Okonogi S. Characterization of potent anticholinesterase plant oil based microemulsion. Int J Pharm 2010;401:32-40.

10. Haze S, Sakai K, Gozu Y. Effects of fragrance inhalation on sympathetic activity in normal adults. Japan J Pharmacol 2002; $90: 247-53$.

11. Shen J, Niijima A, Tanida M, Horii Y, Maeda K, Nagai K. Olfactory stimulation with scent of grapefruit oil affects autonomic nerves, lipolysis and appetite in rats. Neurosci Lett 2005;380:289-94.

12. Tanida M, Niijima A, Shen J, Nakamura T, Nagai K. Olfactory stimulation with scent of essential oil of grapefruit affects autonomic neurotransmission and blood pressure. Brain Res 2005; 1058:44-55

13. Haze S, Sakai K, Gozu Y, Moriyama M. Grapefruit oil attenuates adipogenesis in cultured subcutaneous adipocytes. Planta Med 2010;76:950-5.

14. Uysal B, Sozmen F, Aktas O, Oksal BS, Kose EO. Essential oil composition and antibacterial activity of the grapefruit (Citrus Paradisi. L) peel essential oils obtained by solvent-free microwave extraction: comparison with hydrodistillation. Int J Food Sci Technol 2011;46:1455-61.

15. Aqil M, Ahad A, Sultana Y, Ali A. Status of terpenes as skin penetration enhancers. Drug Discovery Today 2007;12:1061-7.

16. Rhee YS, Choi JG, Park ES, Chi SC. Transdermal delivery of ketoprofen using microemulsions. Int J Pharm 2001;228:161-70.

17. Escribano E, Calpena AC, Queralt J, Obach R, Doménech J. Assessment of diclofenac permeation with different formulations: an anti-inflammatory study of a selected formula. Eur J Pharm Sci 2003;19:203-10.

18. Ngawhirunpat $\mathrm{T}$, Worachun $\mathrm{N}$, Opanasopit $\mathrm{P}$, Rojanarata $\mathrm{T}$, Panomsuk S. Cremophor RH40-PEG 400 microemulsions as transdermal drug delivery carrier for ketoprofen. Pharm Dev Technol 2013;18:798-803.

19. Amato $M$, Isenschmid $M$, Hüppi P. Percutaneous caffeine application in the treatment of neonatal apnoea. Eur J Pediatr 1991;150:592-4.

20. Amato M, Hüppi P, Isenschmid M, Schneider H. Developmental aspects of percutaneous caffeine absorption in premature infants. Am J Perinatol 1992;9:431-4.

21. Schmidt B, Roberts RS, Davis P, Doyle LW, Barrington KJ, Ohlsson A, et al. Caffeine for apnea of prematurity trial group: caffeine therapy for apnea of prematurity. $N$ Engl J Med 2006;354:2112-21.

22. Lupi O, Semenovitch IJ, Treu C, Bottino D, Bouskela E: Evaluation of the effects of caffeine in the microcirculation and edema on thighs and buttocks using the orthogonal polarization spectral imaging and clinical parameters. J Cosmet Dermatol 2007;6:102-7.

23. Hansch C, Leo A, Hoekman D. In exploring QSAR: hydrophobic, electronic and steric constants. Washington, DC: American Chemical Society; 1995.

24. Touitou E, Levi Schaffer F, Dayan N, Alhaique F, Riccieri F. Modulation of caffeine skin delivery by carrier design: liposomes versus permeation enhancers. Int J Pharm 1994;103:131-6.

25. Bolzinger MA, Briançon S, Pelletier J, Fessi H, Chevalier Y. Percutaneous release of caffeine from microemulsion, emulsion and gel dosage forms. Eur J Pharm Biopharm 2008;68:446-51.

26. Zhang J, Michniak Kohn B. Investigation of microemulsion microstructures and their relationship to transdermal permeation of model drugs: ketoprofen, lidocaine and caffeine. Int J Pharm 2011;421:34-44.

27. Djekic L, Primorac M. The influence of cosurfactants and oils on the formation of pharmaceutical microemulsions based on PEG-8 caprylic/capric glycerides. Int J Pharm 2008;352:231-9.

28. Bhatia KS, Gao S, Singh J. Effect of penetration enhancers and iontophoresis on the FT-IR spectroscopy and LHRH permeability through porcine skin. J Controlled Release 1997;47:81-9.

29. Mitragotri S, Anissimov YG, Bunge AL, Frasch HF, Guy RH, Hadgraft J, et al. Mathematical model of skin permeability: an overview. Int J Pharm 2011;418:115-29.

30. Spernath A, Yaghmur A, Aserin A, Hoffman RE, Garti N. Foodgrade microemulsions based on nonionic emulsifiers: media to enhance lycopene solubilization. J Agric Food Chem 2002;50:6917-22.

31. Rowe RC, Sheskey PJ, Quinn ME. Handbook of pharmaceutical excipients. 6th ed. Illinois: Pharmaceutical Press; 2009.

32. Williams AC, Barry BW. Penetration enhancers. Adv Drug Delivery Rev 2012;64:128-37.

33. Jaipakdee N, Limpongsa E, Pongjanyakul T. Optimization of minoxidil microemulsions using fractional factorial design approach. Pharm Dev Technol 2016;21:86-97.

34. Ma H, Yu M, Lei M, Tan F, Li N. A novel topical targeting system of caffeine microemulsion for inhibiting UVB-induced skin tumor: characterization, optimization, and evaluation. AAPS PharmSciTech 2015;16:905-13.

35. Subramanian A, Ananthan S, Vignesh M, Selva Bharathi SP, Thirumarimurugan M. Extraction of grapefruit essential oil from grapefruit peels. Int Proc Chem Biol Environ Eng 2014;74:29-33.

36. Patel MR, Patel RB, Parikh JR, Solanki AB, Patel BG. Effect of formulation components on the in vitro permeation of microemulsion drug delivery system of fluconazole. AAPS PharmSciTech 2009;10:917-23. 
37. Addicks WJ, Flynn GL, Weiner ND, Curl RL. Drug delivery from topical formulations: theoretical prediction and experimental assessment. In: Osborne DW, Amann AH. Eds. Topical drug delivery formulations, NY: Marcel Dekker; 1990. p. 221-44.

38. Nokhodchi A, Shokri J, Dashbolaghi A, Hassan Zadeh D, Ghafourian T, Barzegar Jalali M. The enhancement effect of surfactants on the penetration of lorazepam through rat skin. Int J Pharm 2003;250:359-69.

39. Duracher L, Blasco L, Hubaud JC, Vian L, Marti Mestres G. The influence of alcohol, propylene glycol and 1,2-pentanediol on the permeability of hydrophilic model drug through excised pig skin. Int J Pharm 2009;374:39-45. 